\title{
LA AZAROSA SUPERVIVENCIA DE UN MONUMENTO
}

\author{
Notas en torno a una portada del siglo XVI en el convento \\ de San Juan Bautista, de Coyoacán, D. F.
}

José GuAdalupe Victoria

\begin{abstract}
Para Alfonso Boullosa, en recuerdo de los tiempos de la Prepa 6.
\end{abstract}

Apelo a la benevolencia de mis futuros lectores por comenzar estas líneas con una pequeña digresión autobiográfica. Siendo hijo de comerciantes ambulantes, de niño era frecuente que acompañara a mi madre "a la pla$z^{\prime \prime}$. Puedo decir, con orgullo, que conocí todas las que se hacían en los alrededores de mi pueblo - San Jerónimo Aculco Lídice, D. F.- en diversos días de la semana. Una de las mejores era la de Coyoacán que tenía -tiene aún-lugar los viernes, y que representaba un espectáculo sin igual por los concurrentes y las mercaderías provenientes de diversos sitios. Cualquiera que haya ido "a la plaza" - no importa en qué pueblo de México- jamás olvidará tan maravilloso espectáculo.

Años más tarde tuve la fortuna de hacer mis estudios de bachillerato en la Escuela Nacional Preparatoria No. 6, justo en el momento en que estrenaba su nuevo local. Esto me permitió, día con día, pasar gran parte del tiempo en Coyoacán, en donde era obligado visitar la "plaza" los viernes, el jardín, la iglesia y otros rincones del barrio centenario. Solo o acompañado de algunos amigos, durante las "horas ahorcadas" o después de las clases recorría yo las calles y admiraba las casas y los monumentos de Coyoacán. Nada me hacía pensar, entonces, que andando el tiempo mi vida profesional estaría ligada a la historia y a los edificios de esta parte de la ciudad de México.

Fue en la Preparatoria de Coyoacán donde, gracias a la vehemencia y sabiduría con que trasmitía sus conocimientos históricos el profesor Enrique Mendoza Villarreal, descubrí "mi camino de Damasco" y para bien o para mal decidí estudiar historia; vocación que se deslizó más tarde hacia la historia del arte. Así que, por necesidad profesional y, sobre todo, por gusto, continúo visitando Coyoacán y sus alrededores. De modo que puedo considerarme, sin ninguna pedantería, "vecino honorario" de dicho barrio. 
Si me he permitido esta digresión es porque espero que justifique las siguientes páginas, cuyo objeto fundamental es llamar la atención sobre un monumento que, cotidianamente, pasa inadvertido no sólo para la mayoría de los visitantes y vecinos de Coyoacán, sino aun para los estudiosos del arte novohispano. Tal monumento es la portada que, integrada a uno de los muros de la iglesia, permite el acceso directo a la Capilla del Rosario sin recorrer la nave.

Por todos es conocida la importancia que tuvo el pueblo de Coyoacán en la época prehispánica. Y hay que recordar que fue ahí donde se avecindaton los conquistadores mientras que la ciudad de Tenochtitlan era reconstruida después del sitio padecido (mayo-agosto de 1521). Coyoacán mantuvo su importancia durante la época colonial, tal como lo prueban investigaciones recientes. ${ }^{1}$.

La evangelización del pueblo y sus alrededores fue llevada a cabo, en un primer momento, por los religiosos franciscanos, quienes fundaron un convento, mismo que al correr el tiempo cedieron a los dominicos; en época posterior fue restituido a los franciscanos, quienes lo administran hasta el momento actual. ${ }^{2}$ Del convento de San Juan Bautista dependían varios barrios; cada uno de ellos contaba con su capilla, que era visitada periódicamente por los religiosos del convento grande. Entre esos barrios hay que mencionar los del Niño Jesús, Santa Catarina, San Sebastián Xoco, San Sebastián Axotla, San Sebastián Chimalistac y Santa Cruz Atoyac.

Ahora bien, llama la atención en la arquitectura novohispana del siglo XVI que, mientras que en los grandes conjuntos conventuales se sigue un

1 Pedro Carrasco y Jesús Monjarás-Ruiz, Colección de Documentos sobre Covoacán, México, INAH, Centro de Investigaciones Superiores, 1976, 2 vols. Colección Científica. Fuentes"

${ }^{2}$ El conjunto actual debió construirse a fines de la segunda mitad del siglo XVI, sin que sea posible precisar el año. Véase: George Kubler, Arquitectura mexicana del siglo XVI, México, FCE, 1986, p. 631. Tradicionalmente se acepta que el lugat fue cedido a los dominicos en 1563; ellos lo administraron hasta 1753, año en que tuvo lugar la seculatización. El clero secular lo tuvo a su cuidado hasta 1921, en que la Orden de Frailes Menores lo recuperó. No obstante, Marco Díaz escribe que "los primetos religiosos que ocuparon el sitio fueton los franciscanos; fray Mattín de Valencia vino en 1524 y fue tecibido con una mezcla de admiración y temor por parte de los naturales, mas se pudo establecer' sin dificultad. .. La fundación de los frailes menores quizá tuvo lugar en terrenos situados en la actual Plaza de la Conchita. . La fundación franciscana coexistió con la de los dominicos establecidos en 1529; éstos iniciaton aquí su expansión de tal suette que el de Coyoacán es uno de los más antiguos monasterios dominicos fuera de la capital... La coexistencia de las dos ótdenes se ptolongó hasta 1569, fecha en que el lugat, junto con Tláhuac y Amaquemecan, fue cedido a los dominicos". Matco Díaz, "El convento de San Juan Bautista en Coyoacán", Estudios acerca del arte novobispano. Homenaje a Elisa Vargas Lugo, México, UNAM, Coordinación de Humanidades, 1983, pp. 19-20. 
programa arquitectónico específico, en los conjuntos menores o visitas las soluciones varían. Mencionaremos algunos ejemplos al respecto: en la Sierra Alta del Estado de Hidalgo, las visitas pueden agruparse en dos: capillas cerradas - sería el caso de Malila y de Mezquititlán-y capillas abiertas aisladas, tal como ocurre en Santa Maria Xoxoteco y San Juan Bautista Atzotzintla. ${ }^{3}$ Fenómeno parecido hemos observado en una parte del Estado de Morelos donde se distinguen también capillas cerradas y capillas abiertas; ejemplos de estas últimas son la de Anenecuilco y la de Temimilcingo. ${ }^{4}$ Otro tanto puede decirse de las capillas dependientes del convento de Coyoacán, según lo asentamos en el último artículo citado. Reiteramos aquí nuestras aseveraciones y añadiremos que entre las capillas abiertas - -actualmente convertidas en recintos cerrados- destacan las del Niño Jesús, Santa Catarina y San Sebastián Chimalistac; mientras que el modelo de capilla cerrada estaría representado por la de San Sebastián Axotla, aunque también existieron la de San Sebastián Xoco - totalmente rehecha en el presente siglo-, la de Santa Cruz Atoyac y la de La Conchita, que tal vez debido a la generosidad de un desconocido patrono fue construida de nuevo en el siglo XVIII, constituyendo uno de los ejemplos más bellos del barroco novohispano.

De aquí en adelante nos referiremos a la portada que, como señalamos anteriormente, fue integrada al muro que corre perpendicular a la fachada de la iglesia (fig. 1). Antes de hablar de su diseño y motivos ornamentales, conviene esbozar su "historia". La tradición indica que este arco servía de acceso al atrio en su costado norte, aunque no hay ninguna fuente escrita que así lo consigne. Quizá aquella afirmación venga del hecho siguiente: existen fotografías antiguas, unas publicadas en México en el Tiempo ${ }^{5}$ y otras conservadas en el Archivo Fotográfico del INAH, sito en Culhuacán, en las cuales se ve la mencionada portada en distintos momentos (figs. 2 y 3 ). En la fotografía marcada con el número 19 -del libro citado- aparece la portada parcialmente destruida en la parte superior de la arquivolta y el perímetro del alfiz. En la fotografía número 20 ya puede verse el arco integrado al muro norte del atrio - desaparecido-; las jambas descansan sobre altos zócalos y los restos del alfiz se han perdido completamente. Por encima del arco corre un entablamento rematado, al centro, por una cruz y en los extremos se ven macetones neoclásicos. Una

${ }^{3}$ José Guadalupe Victoria, Arte y Arquitectura en la Sierra Alta. Siglo XVI, México, UNAM, Instituto de Investigaciones Estéticas, 1985.

"José Guadalupe Victoria, "A propósito de un conjunto de capillas abiertas", Anales del Instituto de Investigaciones Estéticas, v. XIII, No. 49, pp. 45-53. México, 1979.

` México en el Tiempo. El marco de la capital, México, Roberto Olavarría Editor, 1946, pp. 32-33. 
tercera fotografía, marcada con el número 21 , muestra la portada tal como puede apreciarse hoy en día y que, de hecho, es la vista que más se ha reproducido en las publicaciones sobre el monumento. Estas vistas de la portada coinciden, más o mienos, con las fotografías conservadas en la fototeca de Culhuacán, aunque es evidente que se trata de tomas distintas. Desgraciadamente ninguna de las fotografías está fechada; pero no es imposi. ble pensar que sean de fines del siglo pasado o de principios del presente (fig. 4).

Da apoyo a esta última afirmación una ilustración incluida en el México a través de los siglos ${ }^{6}$ donde puede verse la portada, cuyo aspecto coincide con el que muestran las distintas fotografías que hemos mencionado. Cabe anotar que para la publicación de tan magno libro, el grabado fue hecho ex-profeso para ilustrar la "historia" de Coyoacán, por R. Canto (fig. 5).

Ahora bien, dado que muchos conocieron la portada como parte del acceso norte del atrio, se ha llegado a convertir en verdad que así fue siempre, lo que, visto con calma, es un error. Dos son las razones en que nos basamos para hacer tal afirmación. La primera de ellas se refiere al esquema utilizado en su composición, y la segunda radica en el tipo de talla que ostentan los motivos decorativos en relación con los del acceso principal del atrio coyoacanense, o sea el del lado poniente. Sin embargo, antes consignaremos algunos datos relacionados con el atrio de este magno convento, los cuales están registrados en el expediente que sobre el inmueble conserva el Archivo de la Dirección de Monumentos Históricos del Instituto Nacional de Antropología e Historia, con sede en el antiguo convento dieguino de Churubusco, D. F.

En 1914 el Consejo Directivo de la Inspección de Bellas Artes tuvo noticia de que el atrio coyoacanense estaba siendo destruido, a pesar de estar protegido por la Ley de monumentos artísticos e históricos decretada el 6 de abril de ese año. El desmán no pudo impedirse, pties la orden de llevarlo a cabo venía del mismísimo presidente de la República. Tal acto de vandalismo - que contemplaba destruir los accesos del atrio, de los cuales por cierto únicamente se mencionan los del norte y del poniente- se

EVicente Riva Palacio, Alfredo Chavero, et al., México a través de los siglos, México, Ed Cumbre, 1953, 5 vols. El grabado mencionado puede verse en el t. II, $p .16$ de esta edición. La ptimera ocasión en que the percaté de que esta portada podía haber formado patte de una antigua capilla fue durante una visita que realicé con mis alumnos del Seminario de Arte Colonial, en el segundo semestre de 1984. Vid José Guadalupe Victoria, Arquitectura y Sociedad en el Valle de México. Siglo XVI (en pteparación), en colaboración con el Seminario de Arte Colonial de la División de Posgrado de la Facultad de Filosofía y Lettas de la UNAM. Ahí se reúnen los trabajos presentados por los participantes en ese seminario; entre ellos figura el de la licenciada Eva Aranda Salgado, quien se encargó de estudiar el convento de Coyoacán 
trataba de justificar alegando que había necesidad de contar con un jardín municipal (iii). Resultaron inútiles los esfuerzos de las autoridades de Bellas Artes para impedir que la picota hiciera de las suyas. Pero lo peor fue que durante varios años y por más que se trató de hacer entender a los vecinos y autoridades de Coyoacán - civiles y religiosas - que el inmueble era un auténtico monumento nacional y que, por lo mismo, debía conservarse sin alteración, no pararon hasta cometer las barbaridades que todos conocemos. En décadas posteriores el conjunto ha sido objeto de varias restauraciones, sin que podamos decir que esté fuera de peligro. Ojalá que obra tan significativa encuentre algún día a su restaurador adecuado y a su historiador idóneo. De utopías y buenos deseos también se vive.

Decíamos líneas atrás que el esquema que presenta esta portada es muy sencillo: se trata de un arco de medio punto que descansa sobre jambas; éstas, a su vez, parecen tener una base y un capitel. El arco es muy ancho y por momentos parece de tres centros; las jambas acentúan tal anchura que, por otra parte, permite el desarrollo de tres fajas de motivos ornamentales cuya volumetría ha permitido su conservación. Los motivos tratados son vegetales casi en su totalidad, distinguiéndose lo que al parecer son hojas de acanto, tanto en las bases como en los capiteles. Las jambas están divididas en dos partes por medio de una vara enlistada; a los lados hay guías con flores y hojas. Tal división se mantiene en el arco, dando la impresión de tener doble arquivolta, repitiéndose los mismos motivos vegetales, aunque enriquecido con dos jarrones con flores, situados en las dovelas de los extremos inferiores. Insistimos en la volumetría con que fueron tallados cada uno de los motivos, pues sin duda es el rasgo que proporciona mayor carácter al monumento.

Este tipo de diseño para portadas fue muy frecuente en el siglo XVI; así lo prueban numerosos ejemplos distribuidos por todo el territorio de la antigua Nueva España. Cierto que en algunas ocasiones la decoración se concentra en las bases de las jambas y en las impostas, en tanto que el alfiz apenas si aparece indicado por medio de pintura, tal como puede verse en Tepeyanco, Tlax. Ejemplos más vistosos son San Lorenzo Totolinga, Méx, Tepeapulco y Molango, Hgo, además de la portada lateral de la iglesia de Huejotzingo, Pue., y la principal de Angahua, Mich., entre los muy numerosos que podríamos citar.

De manera que, dado el diseño que presenta, es posible pensar que esta portada haya pertenecido a una antigua capilla, acaso una de las primeras que se construyeron en la población de Coyoacán o en alguno de sus barrios . De ser así, ¿desde cuándo y por qué se trasladó al convento? Imposible saber con certeza lo uno y lo otro. Lo más que podemos señalar es 
lo siguiente: terminada la conquista espiritual de los indios, las antiguas capillas abiertas fueron convertidas en capillas cerradas, tal como puede apreciarse en Santa Catarina, en San Sebastián Chimalistac y en el Niño Jesús; huelga decir que las que siempre fueron cerradas se mantuvieron como tales. Sin embargo, andando el tiempo y cuando los recursos económicos de las comunidades indígenas fueron mayores, se optó por construir de nuevo las capillas; sería el caso de la de La Conchita.

Empero, es posible pensar que hubo casos en que las comunidades indígenas y los sacerdotes encargados de administrarles la religión, por razones de orgullo, desearan conservar lo que habían podido construir sus mayores, o sea la parte más importante de los antiguos monumentos. Eso podría ayudar a explicar por qué en tantos sitios no se destruyeron las portadas de las primitivas capillas, sino que por el contrario se integraron a las nuevas fábricas, tal como indicamos en otro lugar. ${ }^{7}$ Esta portada de Coyoacán sería un ejemplo más de una obra que debido a su calidad plástica y por razones de orgullo debió pensarse en conservar. Es una pena que no sepamos de cuál capilla procede; pero más triste aún es reconocer que nunca lo sabremos.

La segunda razón por la cual no creemos que esta portada haya constituido uno de los accesos originales del atrio es la sensible diferencia que presenta su talla respecto a la que se aprecia en el acceso principal del conjunto coyoacanense. Obsérvense las fotografías de ambas estructuras y se caerá en la cuenta de cuánta distancia media entre ellas. Claro que puede argumentarse en contra el hecho de que no toda la obra de escultura era realizada por el mismo artista, ni en el mismo tiempo; sin embargo, nos resulta difícil imaginar "dos manos" tan distintas trabajando en sendos monumentos al mismo tiempo. Al contrario, tal diferencia de oficio llevaría a confirmar nuestro parecer en el sentido de que la portada que estudiamos provenga de una capilla ajena al conjunto actual. Pensamos que los accesos norte y sur del atrio debieron presentar una solución similar a la del lado poniente, tanto en diseño como en detalles ornamentales.

Que esta portada pudo ser trasladada de otro lugar tampoco resulta imposible. Es suficiente recordar que en décadas no lejanas, y precisamente en Coyoacán, la portadita que marcaba el acceso a la sacristía, en la iglesia grande, fue trasladada a la casa de un particular (fig. 6). Definitivamente, ni los artistas ni las obras saben cuál será su destino final. Pero lo que resulta una obligación para nosotros es dejar constancia - aunque sea parcialmente- de su azarosa supervivencia.

i José Guadalupe Victoria, "Una portada tequitqui desconocida", Anales del Instituto de Investigaciones Estéticas, v. II, No 48, pp. 63-66 México, 1978. 


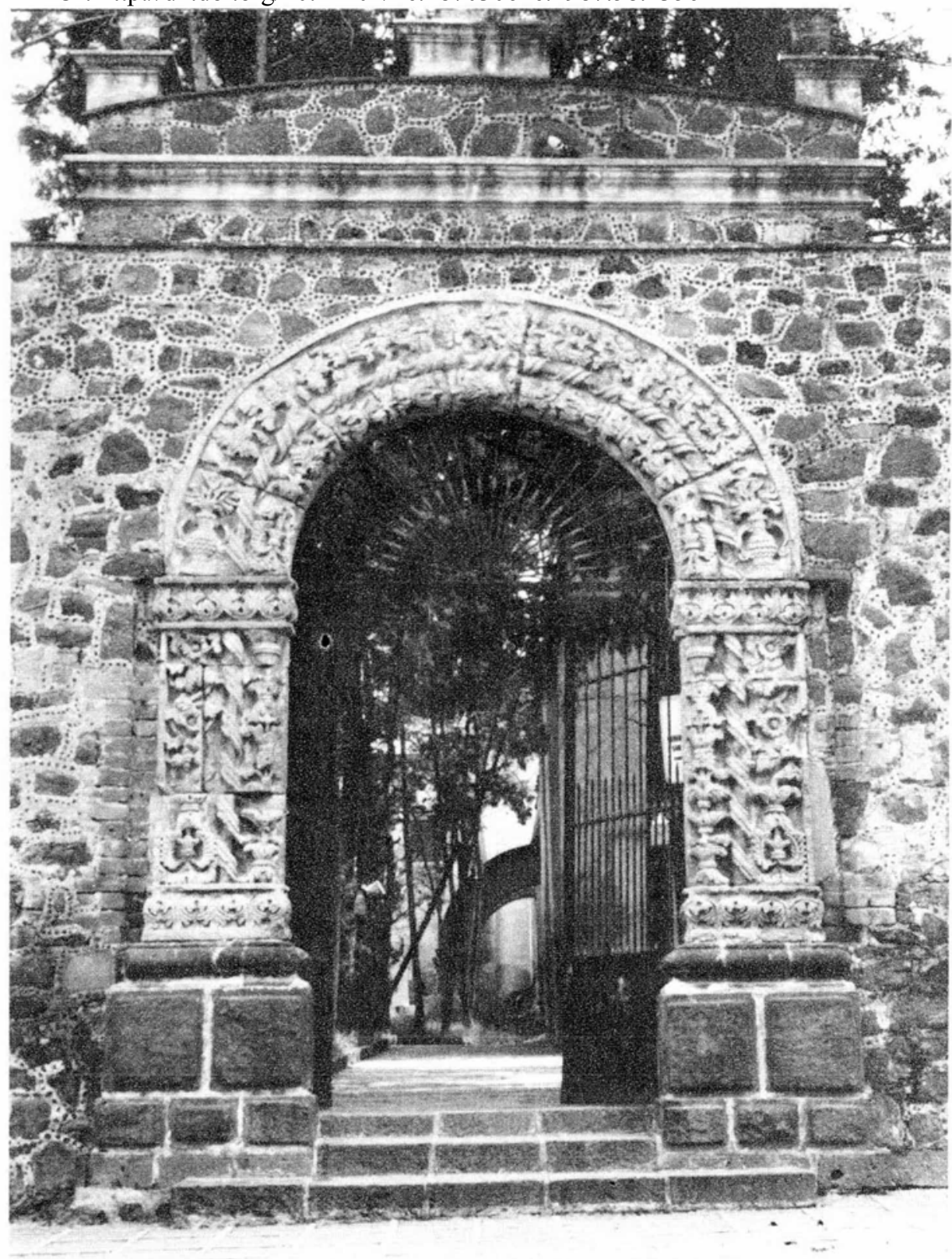

Figura 1. La portada tal como se encuentra actualmente, integrada al muro que corre perpendicular a la fachada de la iglesia y que, al parecer, limitaba el cementerio viejo, según los documentos conservados en el Archivo de Monumentos Históricos del INAH. Nótese la proporción y el diseño que acusan un modelo utilizado con frecuencia en capillas del siglo XVI. Foto: Rafael Rivera. 


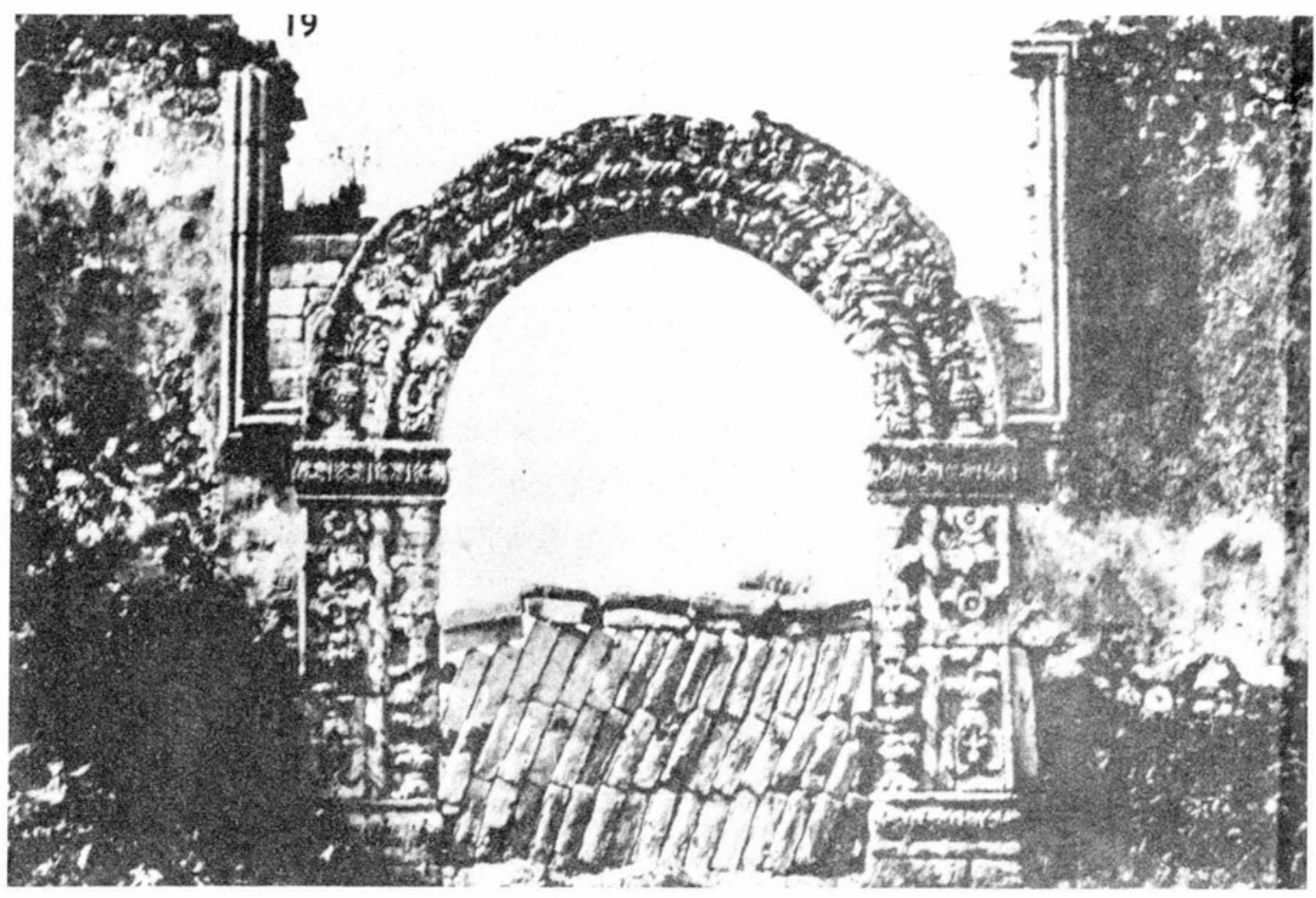

Figura 2. La misma portada según una fotografía publicada en México en el Tiempo, t. II, p. 32. 


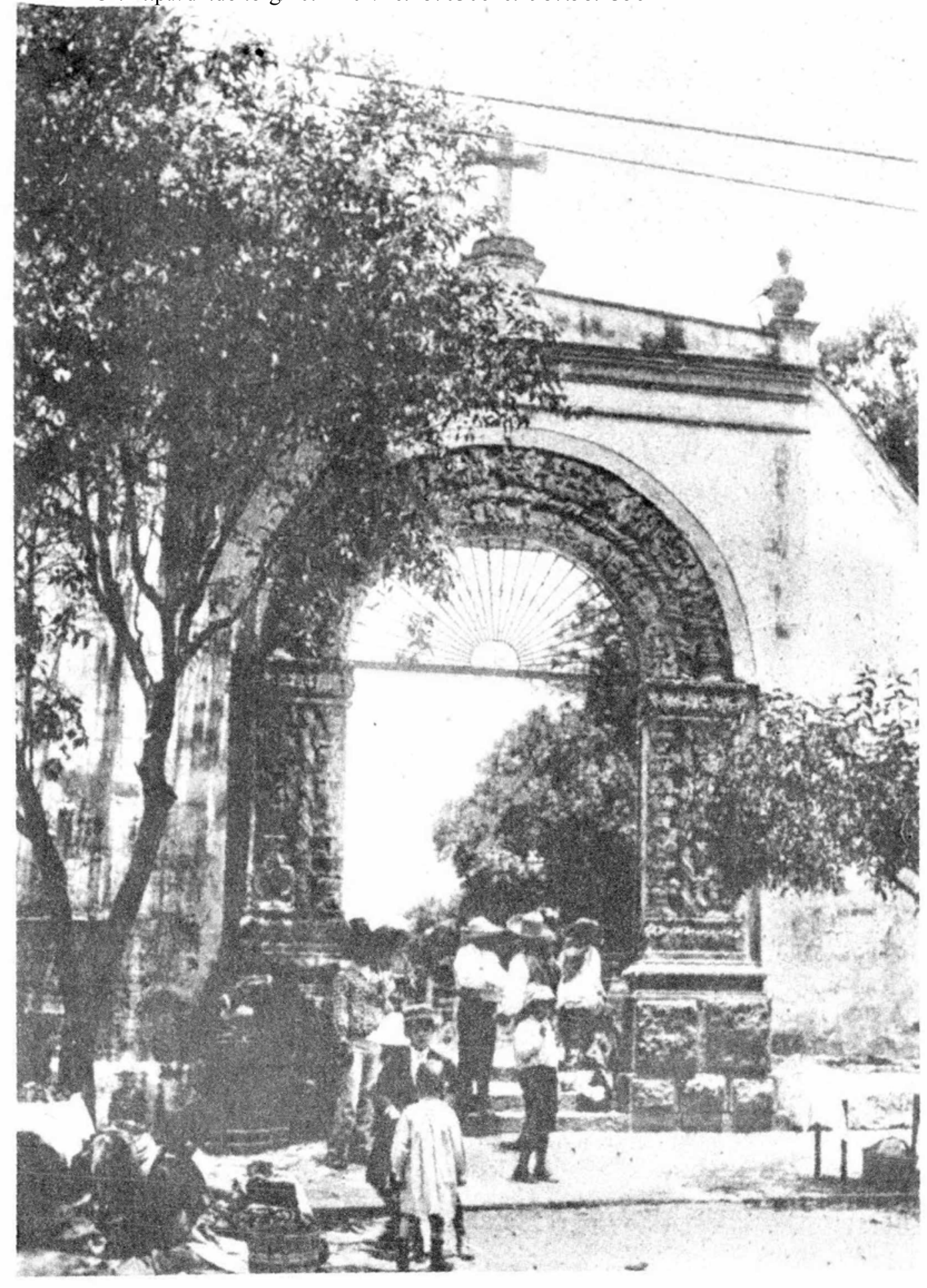

Figura 3. Otra fotografía publicada en México en el Tiempo, t. II, p. 33. Se advierte la destrucción de la arquivolta y el perímetro superior del alfiz. Esta fotografía coincide en términos generales con el grabado que reproducimos en la ilustración número 5. 


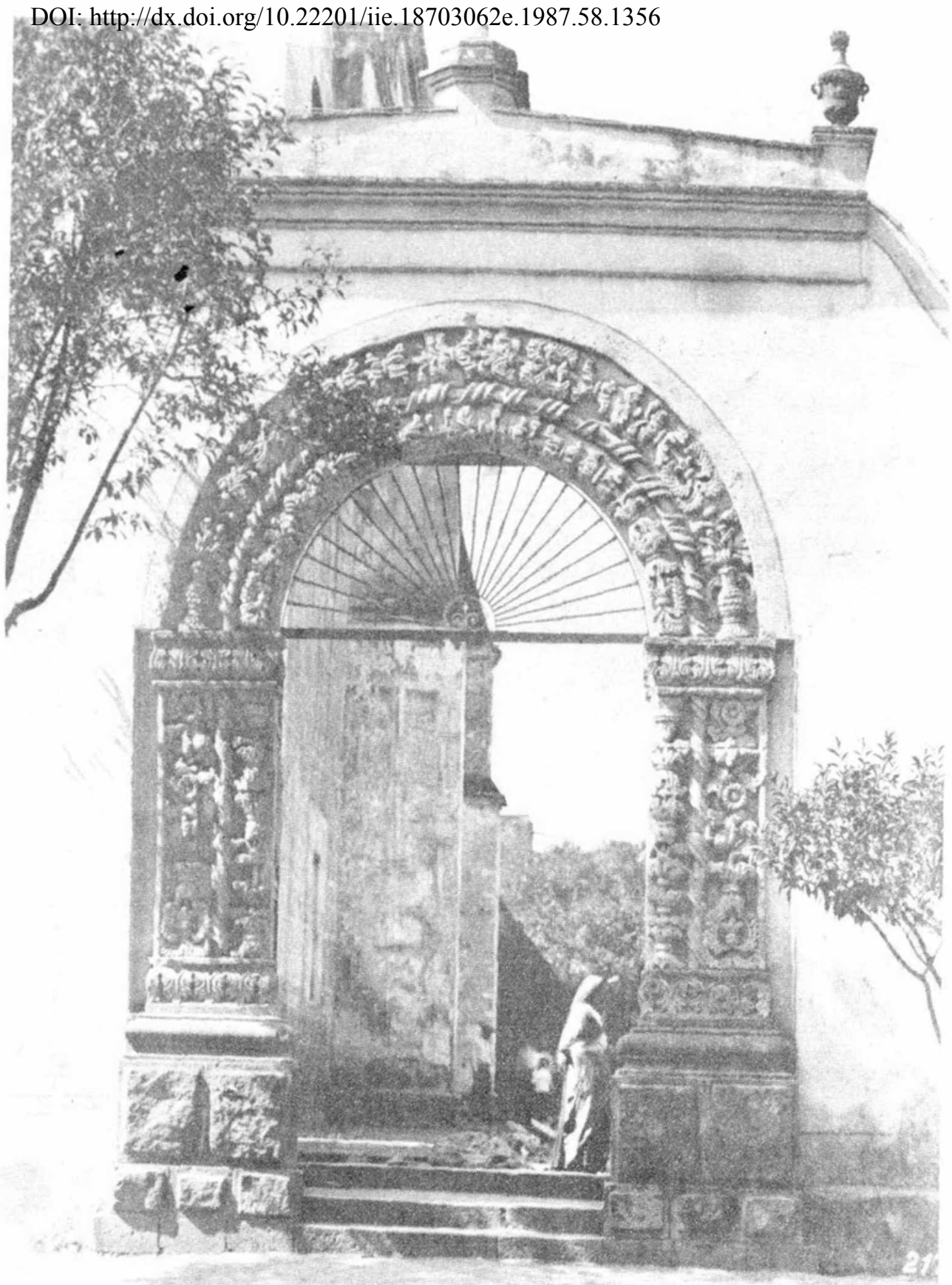

Figura 4. La portada cuando constituía el acceso norte del atrio coyoacanense. Esta fotografía, junto a la que reproducimos con el número 2, deben datar de principios de siglo. Foto: INAH. 


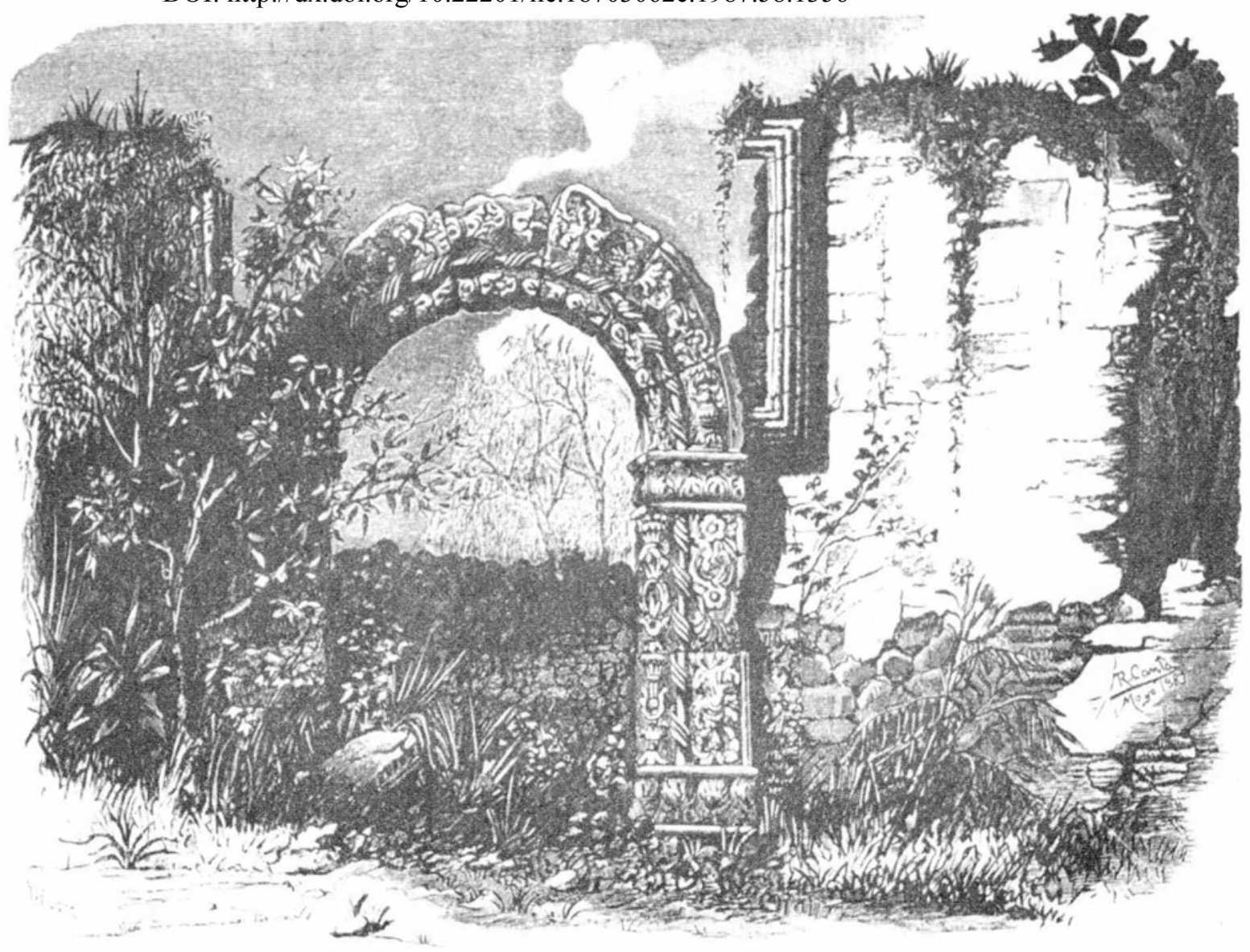

Figura 5. Grabado de R. Canto, fechado en 1883 e incluido en el t. II, p. 16, de] México a través de los siglos. Junto con la ilustración número 3 son la prueba más fehaciente de que el arco formaba parte de una portada. Una inscripción abajo del grabado indica: "tomada del natural". La pregunta que no puede dejar de plantearse es la siguiente: ¿en qué parte del conjunto se encontraba dicha portada?. Sin poder dar una respuesta definitiva consideramos que hay dos posibilidades al respecto: o bien para 1883 ya constituía el acceso septentrional del atrio; o tal vez era la entrada - aunque tanto en la fotografía como en el grabado se ve parcialmente obstruida - del "cementerio viejo" al que aluden los documentos del Archivo de Monumentos Históricos. En el terreno de las posibilidades nos inclinamos por la última. 


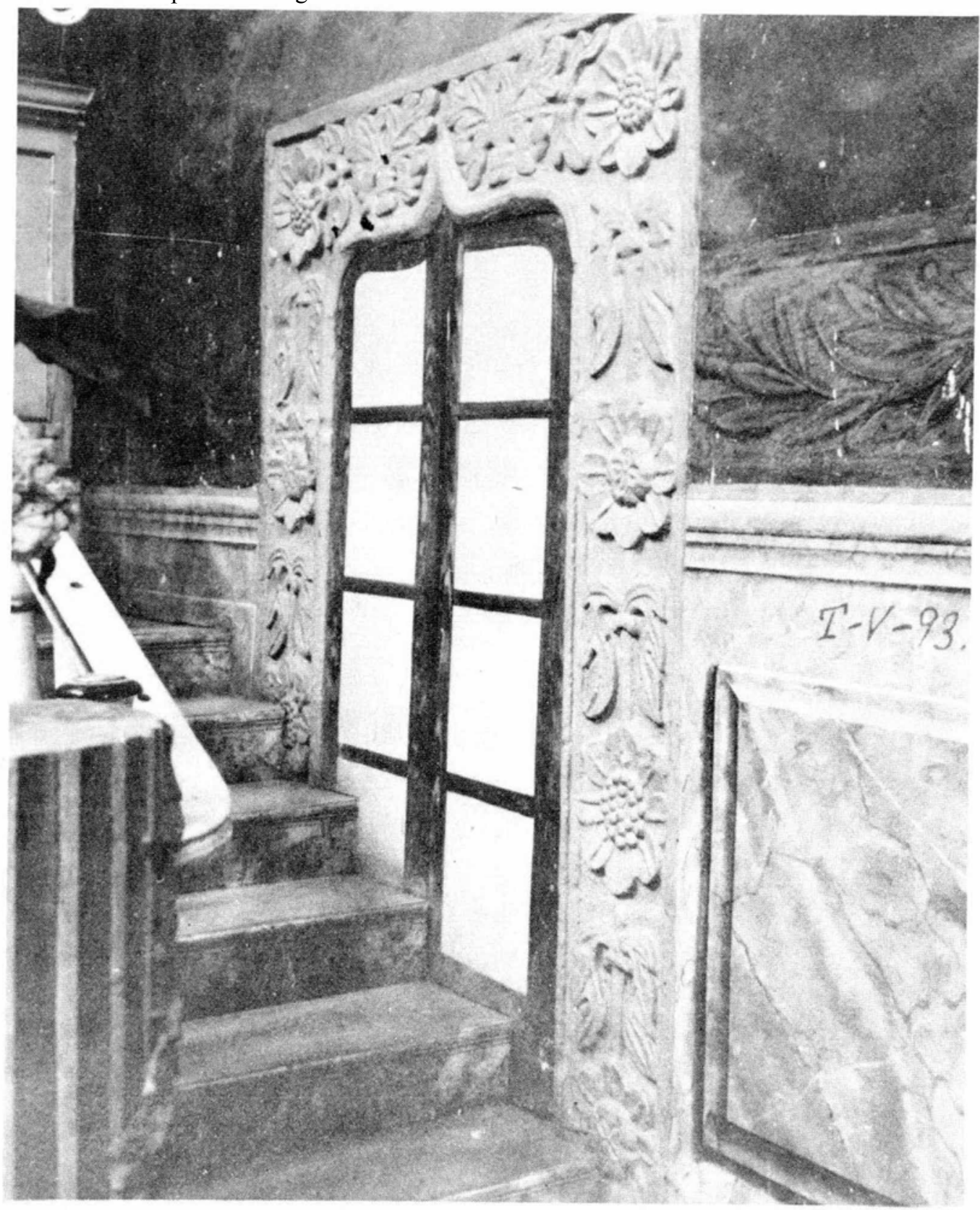

Figura 6. Portada que señalaba la comunicación entre la sacristía y la iglesia. Fue arrancada de su sitio para llevarla a una residencia particular en la calle de Ayuntamiento, en el mismo barrio de Coyoacán. Foto: INAH. 